\title{
Blast Load Analysis on Bridge Subjected to Various Standoff Distance
}

\author{
Priyawakode $^{1}$, D.H. Tupe ${ }^{2}$, G. R. Gandhe ${ }^{3}$ \\ P.G. student ${ }^{1}$, \\ Assistant Professor ${ }^{2}$, \\ HOD of Civil Engineering Department, \\ Deogiri Institute of Engineering \&Management studies ${ }^{3}$, Aurangabad
}

\begin{abstract}
Need for designing important buildings to resist blast masses is growing in the recent time due to the increasing terrorist operations. A bomb explosion can cause very serious injury on the bridge pier. Collapse of one structural member in the vicinity of the source of explosion can also then create integral stress redistributions and lead to crumple of different members and at the end of the entire structure Due to threat from such extreme loading conditions, efforts have been made to develop methods of structural analysis and design to resist blast loads. The evaluation and layout of systems subjected to blast loads require an in depth understanding of blast phenomena and its consequences on numerous structural elements. Blast loads Dynamic masses that want to be cautiously calculated similar to earthquake and wind loads. The study of effect of blast loading on a Bridge pier is carried out. Effects of variable blast source weight are calculated by considering various distances from point of explosion for bridge pier. The calculations of blast load on bridge pier for all cases are carried out by using IS 4991 The blast load is analytically determined as a pressure-time history and structural response predictions are performed with ANSYS using non-linear direct integration time history analyses. The influence of the lateral load response due to blast in terms of peak deflections, normal stress and bending stress is determined. The performance level of bridge pier under blast load is under collapse level for given blast load.
\end{abstract}

Keywords: Dynamic analysis, bridges, blast, explosion, time history, ANSYS

\section{INTRODUCTION}

Impact burdens are viewed as one of the outrageous burdens influencing structures, and even a limited quantity of hazardous can deliver extreme confined harm to the structure. Now and again, this confined extreme harm can possibly advance to worldwide breakdown of the whole structure. A blast begins when a high unstable material is exploded shaping an explosion wave in the material. The explosion wave commonly moves at speeds of $18,000 \mathrm{ft} / \mathrm{s}$ to $20,000 \mathrm{ft} / \mathrm{s}$ and is pressurized at up to $4 \times 106 \mathrm{psi}$ with temperatures in the scope of $8,000^{\circ} \mathrm{F}$. This hot gas is extended, as a fast arrival of vitality happens.

A stun front moving at supersonic speed is framed before this gas and is known as the impact wave or stun front. This wave proliferates outward every which way from the explosion focus. The front of the wave, or the stun front, ventures quicker that the speed of sound. The progression of the air mass behind the stun brings about an outward development of air and flotsam and jetsam causing drag stacking on the structure and is known as the dynamic weight. This dynamic weight stacking is a component of the auxiliary shape, occurrence weight, air thickness, and the touchy material. Figure 1.2 demonstrates a normal bend for episode weight and the dynamic weight after some time. The number and power of residential and global psychological militant exercises, including the September 11, 2001 assault on World Trade Center towers in New York, have increased our worries towards the security of our foundation frameworks. Psychological militants assault targets where human losses and financial outcomes are probably going to be generous. Transportation frameworks have been viewed as alluring targets on account of their openness and potential effects on human lives and monetary action.

\section{A. Blast on Bridges}

The study of the structural and material response of bridges under blast loads are conducted either by experiments or numerical simulations. However, experiments are difficult to be done in full scale and are costly to perform. In addition to that, the other important factor is the difficulty of measuring the various parameters in the field for close-in detonations where the instrument is often destroyed and the failure process is difficult to document. Therefore, numerical solutions are considered an attractive approach to evaluating bridge response to explosions and are very important to support any blast experiments on bridges.

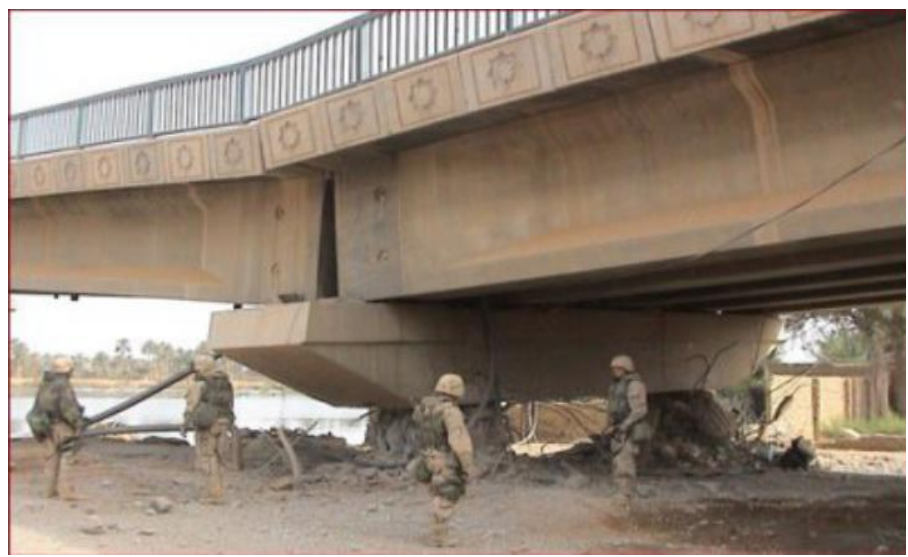

Fig1: A bridge in Iraq damaged by a relatively small number of explosives placed in a Terrorist attack. 


\section{B. Objectives of study}

1. To study effect \& damage pattern of blast on bridge pier.

2. Study of Blast mechanism as per IS 4991

3. Bridge pier analysis with various cross sections such as circular, rectangular using ANSYS workbench.

4. To study stress distribution after blast load is applied and to study load deflection curve

\section{LITERATURE REVIEW}

Shuichi Fujikura[1] This paper reports the exploratory and expository examination of these two kinds of segments under impact stacking. The seismically structured RC and steel jacketed RC segments did not display pliable conduct under impact stacking and bombed in shear at their base as opposed to flexural yielding.

Eric B. Williamson For testing under these conditions, enormous impact burdens should be produced, which are exorbitant and require working with faculty that are fittingly able to complete this work.[2] Exploratory perceptions were utilized to assess the exhibition of a few plan parameters and to decide the limit and disappointment farthest point conditions of strengthened solid parkway connect sections exposed to huge impact loads.

Kiger, Sam[3] A. One-fourth of the straightforward range scaffold and half scale for the nonstop framework were demonstrated considering the fitting limit balance conditions

Z. Yi, A. K.[4] Agrawal To maintain a strategic distance from dock pull-outs and improve the exhibition of impact stacked sections A base measure of containment support ought to be expanded by half over the whole segment tallness.

S.K. Hashemi[5] the consequences of the limited component re-enactments are utilized to evaluate the potential dynamic breakdown reaction of a link stayed scaffold subject to different impact stacking situations.

Mohamed H. Mussa.[6] A thickness of $750 \mathrm{~mm}$ gave off an impression of being exceptionally impervious to the blast of a SDT or compartment for all the examined profundities, and the best opposition was accomplished at a profundity of $8 \mathrm{~m}$, which ought to be considered by architects to guarantee the wellbeing of an underground box burrow when exposed to a fantastic surface blast.

S.K. Hashemi, M.A. Bradford 爪, H.R. Valipour 2016.In the course of recent decades, impact burdens have been perceived as one of the extraordinary stacking occasions that must be considered in the plan of significant structures, for example, link stayed spans

\section{METHODOLOGY WORK STUDY}

The impact burden relies on two central point characterized by the bomb size or charge weight $\mathrm{W}$, and the standoff separation (R) between the impact source and the objective. Consider the structures exposed to a shoot proportional in respect some $\mathrm{kg}$ of TNT at a specific standoff separation

\section{Numerical Model}

Because of the multifaceted nature of cement, its constitutive relations contrast from the diverse burden case. For this situation, a few diverse constitutive models of cement were proposed. The elastoplastic constitutive model dependent on the addition

Hypothesis is utilized to depict the constitutive relations of cement. This model sessile-Warnke's five-parameter yield paradigm, uniform quality foundation and related stream rule. Due to the extraordinary structure style of the steelsolid composite bar to concrete-filled steel rounded segment joints, the conduct varies in the better place of cement. The solid in the center territory of cement filled steel rounded limited by the steel cylindrical is under triaxial burden cases. As per the numerical investigation and test results, the Hanlinhai' model is sensible and solid by utilizing the repression record to characterize the solid limited by the steel cylindrical.

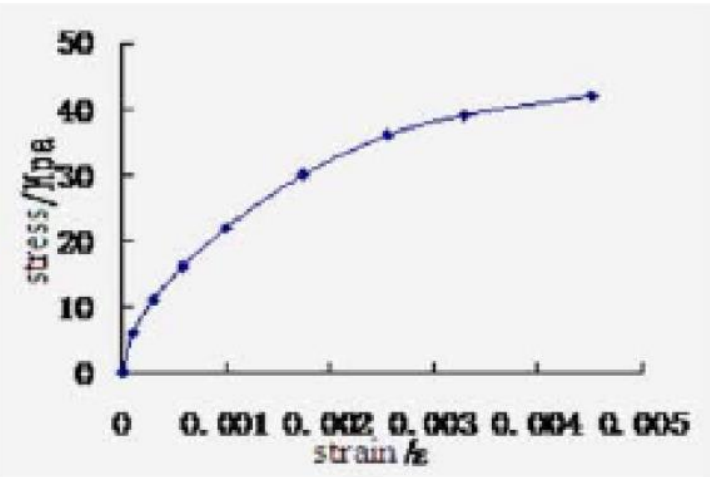

Fig2: Stress Strain Relationship

\section{PROBLEM STATEMENT}

- Type of structure: Bridge Structure

- Height of bridge: $5 \mathrm{M}$

- Total span: $19 \mathrm{M}$

- Width : $12 \mathrm{M}$

- Circular Pier Dia. : 1M

- Rectangular Pier: 1x0.9M

- Explosive charge weight: $200 \mathrm{~kg}, 500 \mathrm{~kg}, 800 \mathrm{~kg}$, $1000 \mathrm{~kg}$

- Support : Fixed

\section{RESULT AND DISCUSSION}

\section{A. ANSYS model For Circular Pier}

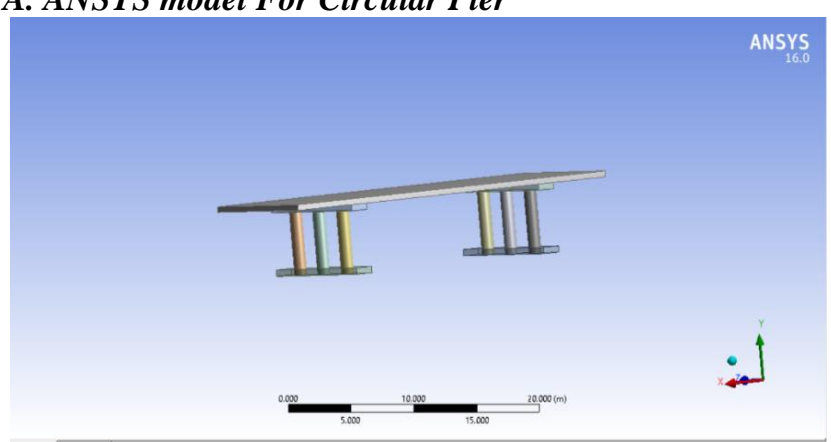

Fig3 Modelling in ANSYS 
Table 1 total deformation for $200 \mathrm{~kg}$

\begin{tabular}{|c|c|c|c|c|}
\hline \multicolumn{5}{|c|}{ TOTAL DEFORMATION 200 KG } \\
\hline TIME (sec) & 15 FEET & 30 FEET & 50 FEET & 100 FEET \\
\hline 0.1 & 0 & 0 & 0 & 0 \\
\hline 0.2 & 0.01332 & 0.01047 & 0.00314 & 0.00523 \\
\hline 0.3 & 0.02663 & 0.02093 & 0.00628 & 0.00105 \\
\hline 0.4 & 0.03995 & 0.0314 & 0.00942 & 0.00157 \\
\hline 0.5 & 0.05327 & 0.04186 & 0.01256 & 0.00209 \\
\hline 0.6 & 0.06659 & 0.05233 & 0.0157 & 0.00262 \\
\hline 0.7 & 0.0799 & 0.06279 & 0.01884 & 0.00314 \\
\hline 0.8 & 0.09322 & 0.07326 & 0.02198 & 0.00366 \\
\hline 0.9 & 0.10654 & 0.08373 & 0.02512 & 0.00419 \\
\hline 1 & 0.11985 & 0.09419 & 0.02825 & 0.00471 \\
\hline
\end{tabular}

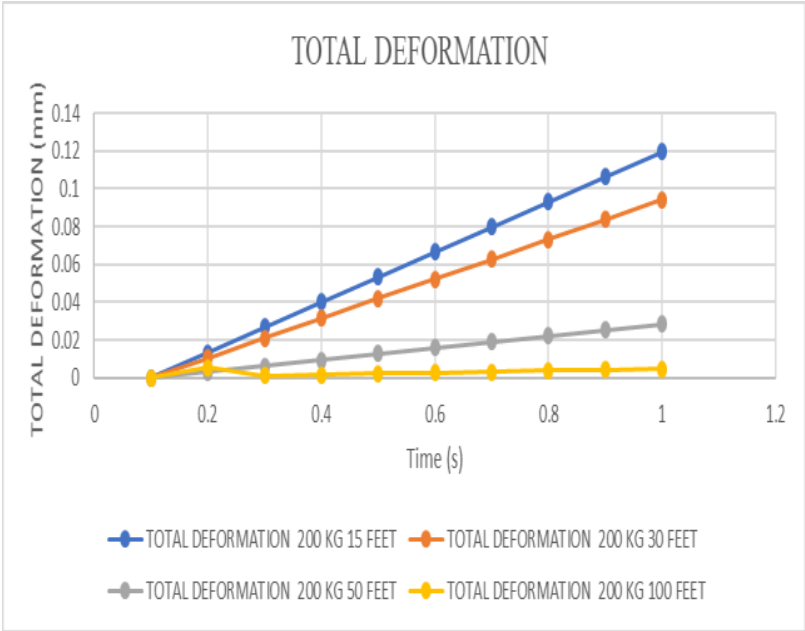

Graph1. Deformation for Blast Load 200kg

Table 2. Total Deformations For $500 \mathrm{Kg}$

\begin{tabular}{|c|c|c|c|c|}
\hline \multicolumn{5}{|c|}{ TOTAL DEFORMATION 500 KG } \\
\hline TIME & 15 FEET & 30 FEET & 50 FEET & 100 FEET \\
\hline 0.1 & 0 & 0 & 0 & 0 \\
\hline 0.2 & 0.01332 & 0.01132 & 0.00419 & 0.00084 \\
\hline 0.3 & 0.02663 & 0.02264 & 0.00837 & 0.00167 \\
\hline 0.4 & 0.03995 & 0.03396 & 0.01256 & 0.00251 \\
\hline 0.5 & 0.05327 & 0.04528 & 0.01674 & 0.00335 \\
\hline 0.6 & 0.06659 & 0.0566 & 0.02093 & 0.00419 \\
\hline 0.7 & 0.0799 & 0.06792 & 0.02512 & 0.00502 \\
\hline 0.8 & 0.09322 & 0.07924 & 0.0293 & 0.00586 \\
\hline 0.9 & 0.10654 & 0.09056 & 0.03349 & 0.0067 \\
\hline 1 & 0.11985 & 0.10187 & 0.03767 & 0.00753 \\
\hline
\end{tabular}

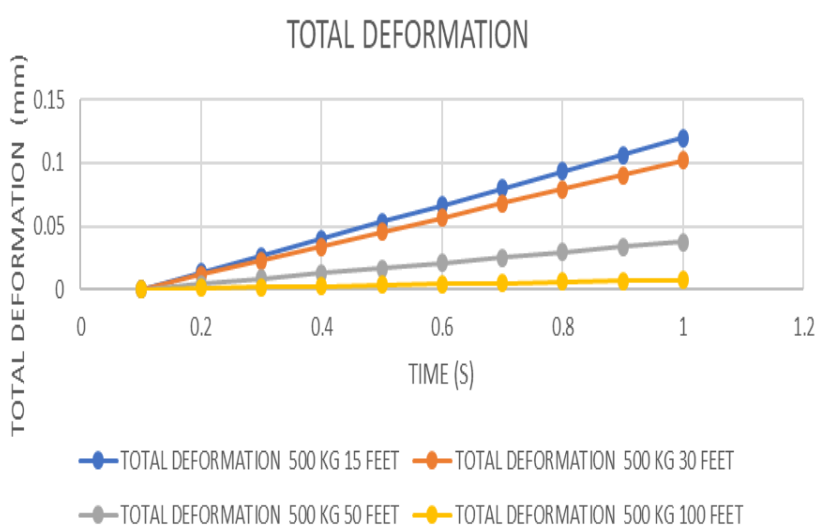

Graph2. Total Deformations for $500 \mathrm{Kg}$

Table 3. Total Deformation for $800 \mathrm{Kg}$

\begin{tabular}{|c|c|c|c|c|}
\hline \multicolumn{5}{|c|}{ TOTAL DEFORMATION 800 KG } \\
\hline TIME & 15 FEET & 30 FEET & 50 FEET & 100 FEET \\
\hline 0.1 & 0 & 0 & 0 & 0 \\
\hline 0.2 & 0.02131 & 0.02094 & 0.00837 & 0.00094 \\
\hline 0.3 & 0.04262 & 0.04187 & 0.01675 & 0.00188 \\
\hline 0.4 & 0.06392 & 0.0628 & 0.02512 & 0.00283 \\
\hline 0.5 & 0.08523 & 0.08374 & 0.03349 & 0.00377 \\
\hline 0.6 & 0.10654 & 0.10467 & 0.04186 & 0.00471 \\
\hline 0.7 & 0.12784 & 0.12561 & 0.05023 & 0.00566 \\
\hline 0.8 & 0.14915 & 0.14654 & 0.05861 & 0.00659 \\
\hline 0.9 & 0.17046 & 0.16748 & 0.06698 & 0.00753 \\
\hline 1 & 0.19177 & 0.18841 & 0.07535 & 0.00848 \\
\hline
\end{tabular}

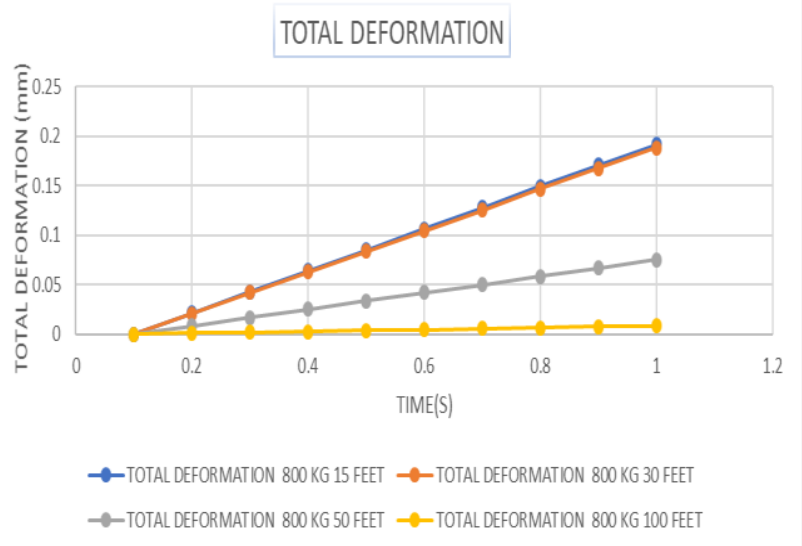

Graph 3. Total Deformations for $800 \mathrm{Kg}$

Table 4. Total Deformations for $1000 \mathrm{Kg}$ TOTAL DEFORMATION $1000 \mathrm{KG}$

\begin{tabular}{|c|c|c|c|c|}
\hline TIME & 15 FEET & 30 FEET & 50 FEET & 100 FEET \\
\hline 0.1 & 0 & 0 & 0 & 0 \\
\hline 0.2 & 0.02131 & 0.01811 & 0.00942 & 0.00157 \\
\hline 0.3 & 0.04262 & 0.03622 & 0.01884 & 0.00314 \\
\hline 0.4 & 0.06392 & 0.05433 & 0.02826 & 0.00471 \\
\hline 0.5 & 0.08523 & 0.07245 & 0.03768 & 0.00628 \\
\hline 0.6 & 0.10654 & 0.09056 & 0.0471 & 0.00785 \\
\hline 0.7 & 0.12784 & 0.10866 & 0.05651 & 0.00942 \\
\hline 0.8 & 0.14915 & 0.12678 & 0.06593 & 0.01099 \\
\hline 0.9 & 0.17046 & 0.14489 & 0.07535 & 0.01256 \\
\hline 1 & 0.19177 & 0.16301 & 0.08477 & 0.01413 \\
\hline
\end{tabular}




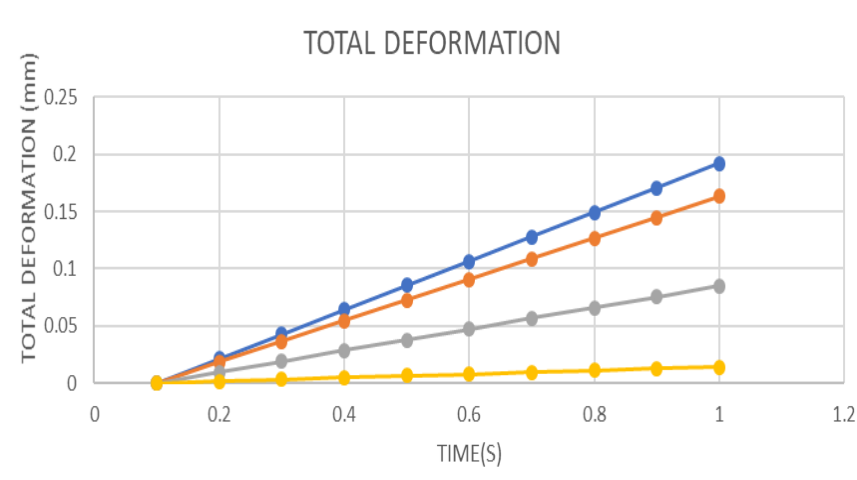

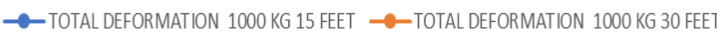

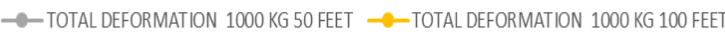

Graph 4. Total Deformations for $1000 \mathrm{Kg}$

\section{CONCLUSION}

1) It is observed that in circular pier maximum deformation is obtain at $15 \mathrm{ft}$ and minimum deformation at $100 \mathrm{ft}$. Also observed that for all weight of blast, there is some reduction in deformation, Normal strain, equivalent strain, strain energy, and normal stress. Also studied blast resistant bridge pier theories, the enhancement of building security against the effects of explosives in both architectural and structural point of view and the analysis techniques that should be carried out. In the present, studied about Blast mechanism for different terms related to blast and characteristics of blast. Also studied various types of blast such as commonly used blast TNT and Blast Mitigation Techniques and their applications. Blast can create significant effect on bridge. So, it's necessary to design important bridges for blast load. However, for $15 \mathrm{ft}$ and $30 \mathrm{ft}$ the deformation values are nearly same in circular pier for $800 \mathrm{~kg}$.

2) It is also observed that in Rectangular pier, maximum deformation is obtained at $15 \mathrm{ft}$ and minimum deformation at $100 \mathrm{ft}$ Also observed that for all weight of blast, there is some reduction in deformation, Normal strain, equivalent strain, strain energy, and normal stress.

3) All model having maximum total deformation at 15 feet for circular and rectangular.

4) All model having minimum total deformation at 100 feet for circular and rectangular.

5) Circular pier has maximum deformation which is $22.01 \%$ at 15 feet as compared to rectangular pier for $200 \mathrm{~kg}$ and $500 \mathrm{~kg}$ TNT weight.

6) Circular pier has maximum deformation which is $23.74 \%$ at 15 feet as compared to rectangular pier for $800 \mathrm{~kg}$ and $1000 \mathrm{~kg}$ TNT weight.
7) The comparison between circular pier and rectangular pier, it is observed that in circular pier has maximum total deformation as compared to rectangular pier.

8) After comparing all the result of a circular pier and rectangular pier, rectangular pier will become better for future use in construction as compared to circular pier under the blast load condition

9) It is observed that deformation is more when its standoff distance is near to pier.

10) According to validation it is observed that both deformations is near about same so it concludes that this project work in right path.

\section{REFERENCES}

[1] “Explosion Resistant Buildings[1]”byT. Bangash, M.Y.Bangash

[2] AASHTO (2002).[2] Standard Specifications for Highway Bridges, AmericanAssociation of State Highway and Transportation Officials, Washingtong, D.C.

[3] AASHTO. (2003).[3] "Guide ManuaL for Condition Evaluation and Load and Resistance Factor Rating (LRFR) of Highway Bridges."AASHTO, 448

[4] Shuichi Fujikura and Michel Bruneau (2011)[4] “Arch Experimental Investigation of Seismically Resistant Bridge Piers under Blast Loading",Journal of Bridge Engineering,Vol.16(6) 63 $71 @$ ASCE,ISSN

[5] ZeynepKoccaz, FatihSutcu, NecdetTorunbalci(October 12-17, 2008)[5]Architectural And Structural Design For Blast Resistant Buildings, The 14th World Conference on Earthquake

[6] Z. Yi, A. K. Agrawal, M. Ettouney, and S. Alampalli (2014)[6] "Blast Load Effects on Highway ,Journal of Bridge Engineering,Vol.19(4)@ASCE,ISSN ]

[7] Eric B. Williamson, OguzhanBayrak, Carrie Davis and G. Daniel Williams (2011)[7] "Performance of Bridge Columns Subjected to Blast Loads. I: Experimental Program"Journal of Bridge Engineering,Vol.16 @ ASCE,ISSN

[8] Eric B. Williamson, OguzhanBayrak, Carrie Davisand G. Daniel Williams (2011)[8] "Performance of Bridge Columns Subjected to Blast Loads. II: Results and Recommendations"Journal of Bridge Engineering,Vol.16(6) @ ASCE,ISSN

[9] Kiger, Sam A., Hani A. Salim, and Ahmed Ibrahim(2011)[9] "Bridge Vulnerability Assessment and Mitigation against Explosions",LSU,IOT

[10] ManmohanDassGoel and Vasant A. Matsagar(2014)[10]"BlastResistant Design of Structures “,COEP,2014

[11] S.K. Hashemi, M.A. Bradford 爪, H.R. Valipour(2016)[11] 'Dynamic response of cable-stayed bridge under blast load 'Engineering Structures 127(2016), 719-735

[12] S.K. Hashemi, M.A. Bradford 爪, H.R. Valipour(2017)[12] 'Dynamic response and performance of cable-stayed bridges under blast load: Effects of pylon geometry' Engineering Structures 137(2017),50-66

[13] Yuxin Pan a, $\Uparrow$, Carlos E. Ventura a, Moe M.S. Cheung b(2017)[13] 'Performance of highway bridges subjected to blast loads'Engineering Structures 151(2017),788-801

[14] Mohamed H. Mussa*, Azrul A. Mutalib, Roszilah Hamid, Sudharshan R. Naidu,(2017)[14] "Assessment of damage to an underground box tunnel by a surface explosion "Science Direct 66(2017) 64-76

[15] S. Chung Kim Yuena, A. Butlera, H. Bornsteinb, A Choletc(2018)[15] 'The influence of orientation of blast loading on quadrangular plates', Thin walled structures 131(2018) 827-837 